\title{
Treat AIDS-Related Neurologic Disease
}

National Cancer Institute

\section{Source}

National Cancer Institute. Treat AIDS-Related Neurologic Disease. NCI Thesaurus. Code C19090.

Develop strategies for assessing, preventing, and treating central and peripheral nervous system dysfunction in the course of HIV infection. 